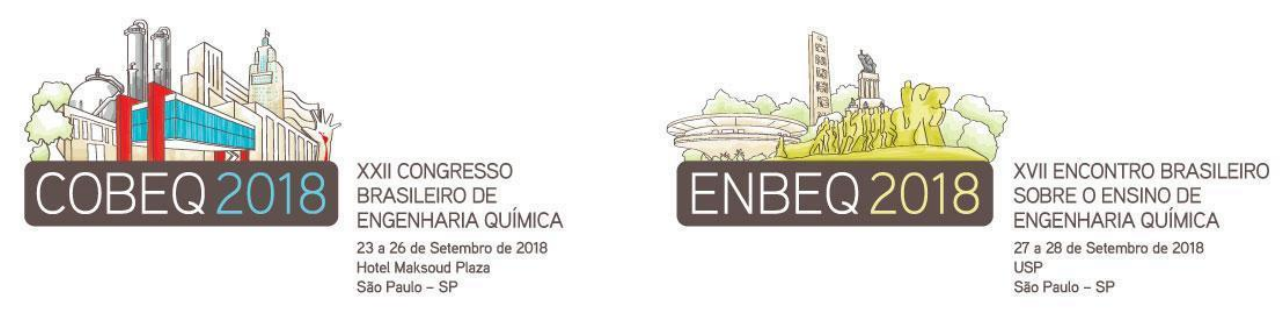

\title{
TRATAMENTO DO EFLUENTE GERADO NA PRODUÇÃO DO BIODIESEL POR MEIO DA ADSORÇÃO COM PÓ DE ALTO-FORNO E PÓ DE MINÉRIO
}

\author{
XAVIER IPAS ${ }^{1}$, ALVES LF $^{1}$, FÉLIX JSAO ${ }^{1}$ e CASTRO FD ${ }^{1}$ \\ ${ }^{1}$ Centro Universitário do Leste de Minas Gerais, Departamento de Engenharia Química \\ E-mail para contato: ivanpedroasx@gmail.com, lorenaalves65@yahoo.com.br
}

\begin{abstract}
RESUMO - O presente trabalho teve como objetivo tratar o efluente gerado na produção do biodiesel, utilizando pó de alto forno e pó de minério, por meio do método de adsorção. Os resíduos foram classificados quanto à granulométrica, observando-se maior fração de partículas com diâmetro inferior a 0,075 e superior a 2,75 mm. Após essa etapa, quantificou-se a DQO do efluente estudado, que apresentou valor de 304111,11 mg de $\mathrm{O}_{2} / \mathrm{L}$. A turbidez (29000 FAU) e o pH (9,3) do efluente também se mostraram altos. Nas etapas posteriores, para se avaliar as condições ótimas de adsorção, foram obtidas as condições mais favoráveis de tratamento para o pH (entre 2 e 3); concentração de resíduo $(1 \mathrm{~g} / \mathrm{L})$; e granulometria do resíduo (partículas com diâmetro inferior a 0,075 mm). A partir do estudo cinético, observou-se que, a remoção da DQO nas primeiras horas foi aproximadamente $30 \%$, seguindo um modelo de pseudo-primeira ordem, enquanto no equilíbrio (24 horas) foi cerca de $80 \%$, para ambos os resíduos.
\end{abstract}

\section{INTRODUÇÃO}

$\mathrm{Na}$ busca por novas fontes de energia, muitas pesquisas têm sido desenvolvidas a respeito do biodiesel, que é um combustível menos poluente do que aqueles oriundos do petróleo (Gonçalves, 2015). Porém, no seu processo produtivo convencional (através da reação de transesterificação com óleo vegetal e metanol), há grande formação de efluente líquido na etapa de purificação. Essa problemática, aliada ao descarte inadequado de efluentes, merece grande atenção, por apresentar alto potencial poluidor, em especial aos corpos hídricos nos quais os efluentes são descartados (Santos, 2013).

A aplicação de resíduos siderúrgicos industriais em tecnologias de tratamento de efluentes apresenta caráter inovador e sustentável, visto o reaproveitamento de resíduo sem valor agregado (Oliveira, 2014). Aliado a isso, o processo de adsorção tem ganhado espaço, sendo uma técnica de tratamento de elevada eficiência e amplamente utilizada para a remoção de compostos orgânicos dissolvidos em efluentes. Neste panorama, a utilização de resíduos siderúrgicos na adsorção é promissora (Andrade et al., 2012; Santos, 2013).

O presente trabalho teve como objetivos avaliar os parâmetros físico-químicos (demanda química de oxigênio (DQO), $\mathrm{pH}$, turbidez e condutividade) do efluente, caracterizar os resíduos siderúrgicos quanto à granulometria. Por meio de ensaios de adsorção, foram 


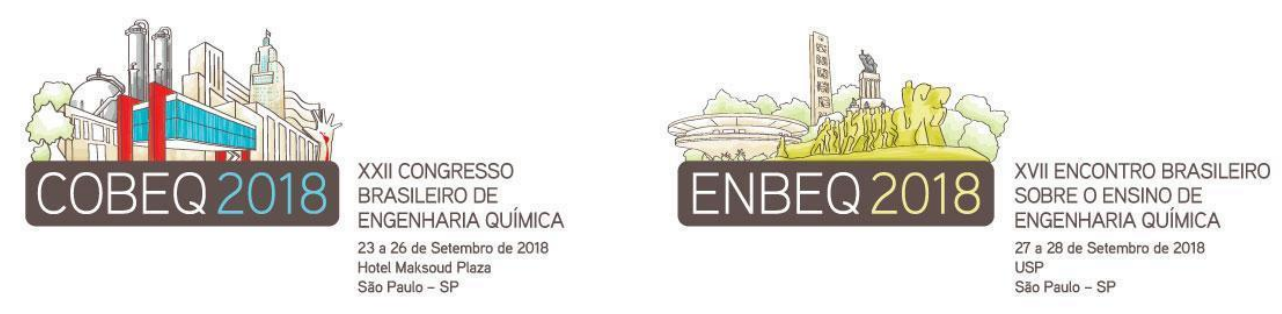

estabelecer as condições ótimas para o processo, como $\mathrm{pH}$ do efluente, granulometria e concentração do resíduo, a fim de se realizar o estudo cinético e avaliar a eficiência da adsorção no processo de tratamento do efluente.

\section{METODOLOGIA}

O pó de Alto-Forno (PAF) e o pó de minério (PM), cedidos por uma empresa siderúrgica regional, foram caracterizados quanto à sua granulometria, utilizando um agitador de peneiras marca Solotest. O efluente submetido ao tratamento foi gerado na primeira lavagem do biodiesel, produzido pela reação de transesterificação com óleo residual de fritura e metanol, catalisada por hidróxido de potássio. O efluente foi caracterizado quanto à sua DQO, turbidez, condutividade e $\mathrm{pH}$ (APHA, 2005).

Os parâmetros ótimos foram definidos a partir de testes de adsorção, variando-se o pH do efluente, concentração e granulometria de resíduo. Para se definir pH ótimo, três amostras do efluente foram preparadas, sendo a amostra $1 \mathrm{com}$ o pH 2,5 (ácido), amostra $2 \mathrm{com} \mathrm{pH} \mathrm{6,8}$ (neutro) e amostra $3 \mathrm{com}$ o pH 9,0 (básico), fixando-se concentração e granulometria do resíduo, volume do efluente $(20 \mathrm{~mL})$ e tempo de reação. Para a concentração ótima de resíduo, utilizaram-se quatro concentrações diferentes $(1,10,50$ e $100 \mathrm{~g} / \mathrm{L})$. Para granulometria ótima, utilizaram-se partículas com diâmetros de 0,075, 0,5 e $1,7 \mathrm{~mm}$.

Após estabelecidas as melhores condições de tratamento, realizou-se estudo cinético. O efluente foi submetido à adsorção com o PAF e o PM por 24 horas, e, do início até o final $(0 \mathrm{a}$ $1440 \mathrm{~min}$ ), foram realizadas análises de DQO. A partir dos resultados cinéticos, avaliou-se a eficiência da adsorção com ambos os resíduos siderúrgicos no tratamento do efluente do biodiesel.

\section{RESULTADOS E DISCUSSÕES}

A partir da análise granulométrica do PAF e PM, foram constatadas variações dos diâmetros dos resíduos. Observou-se uma maior fração de finos de diâmetro inferior a 0,075 mm para o PAF e uma maior fração de partículas com diâmetro superior a 2,75 mm para o PM.

Com relação ao efluente bruto, este apresentou pH 9,3, turbidez de 29000 FAU, condutividade de $1884 \mu \mathrm{S} / \mathrm{cm}$ e DQO de $304111,11 \mathrm{mg}$ de $\mathrm{O} /$. Verifica-se que a água residuária possui um valor muito elevado de DQO, justificado pela alta concentração de carga orgânica nele presente.

Nos ensaios para definir o pH ótimo de adsorção, a partir da DQO do efluente tratado, observou-se maior remoção de DQO nas amostras com pH 2,5, conforme apresentado na Figura 1 A. A partir do pH ótimo, realizaram-se ensaios para diferentes diâmetros e concentrações dos resíduos, sendo constatado melhor resultado na remoção da DQO para $1 \mathrm{~g} / \mathrm{L}$ de resíduo (Figura 1 B) e para o menor diâmetro obtido na classificação granulométrica (Figura 1 C). Estas condições foram válidas para ambos os resíduos avaliados neste estudo. 


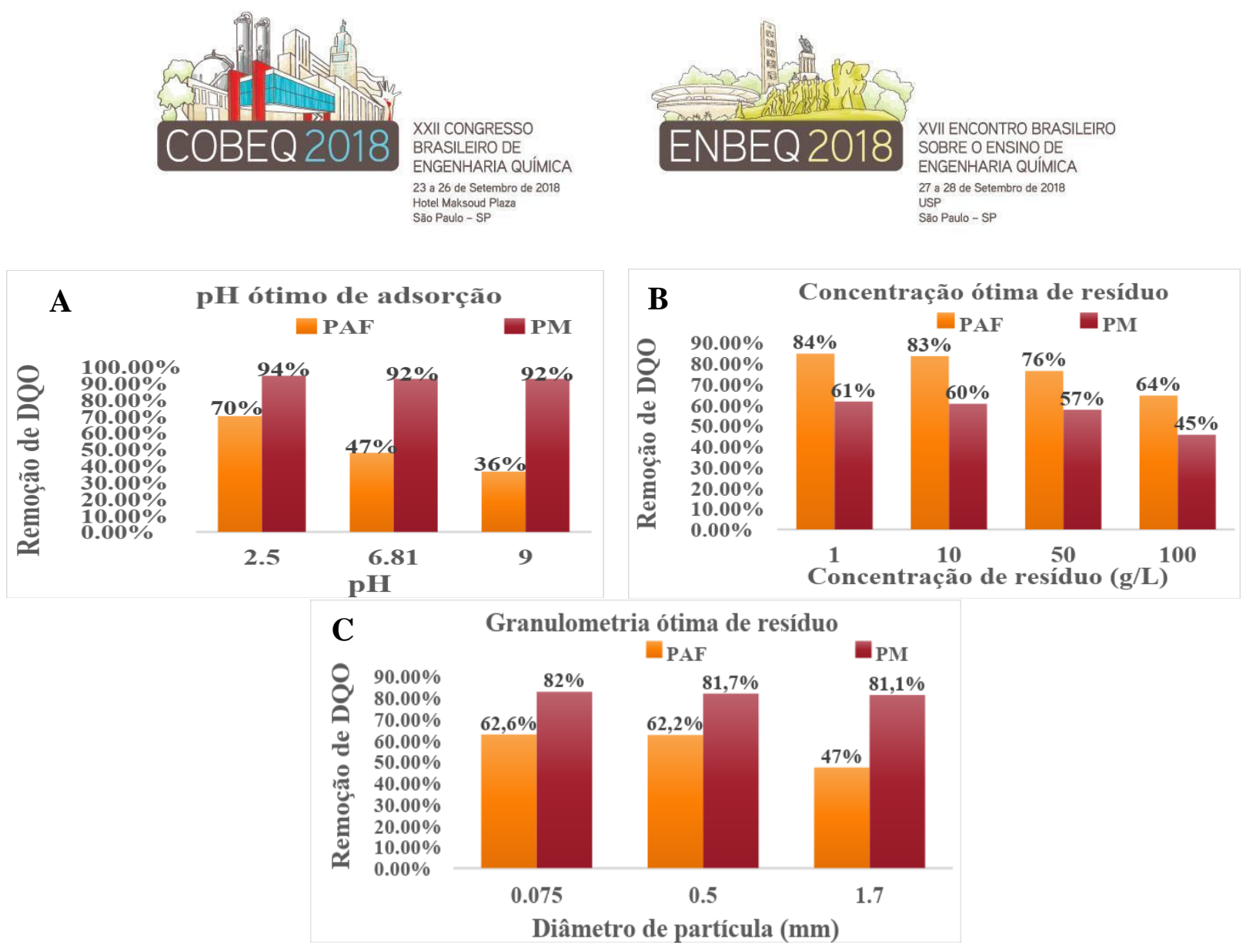

Figura 1 - pH ótimo de efluente (A), concentração ótima (B) e granulometria ótima de resíduo (C) para adsorção.

Durante o estudo cinético, observou-se que para os momentos iniciais da adsorção (entre 0 e $120 \mathrm{~min}$ ), a remoção de DQO permaneceu em torno de 55 a 62,5\% da DQO do efluente inicial. Após os 120 min de adsorção, a remoção de DQO aumenta para cerca de $90 \%$ dando ao efluente uma aparência mais límpida do que antes. O equilíbrio foi constatado no final dos 1440 min (24h) de adsorção, conferindo ao efluente uma remoção de DQO de aproximadamente $82 \%$ tanto para o PAF, quanto para o PM (figura 2).

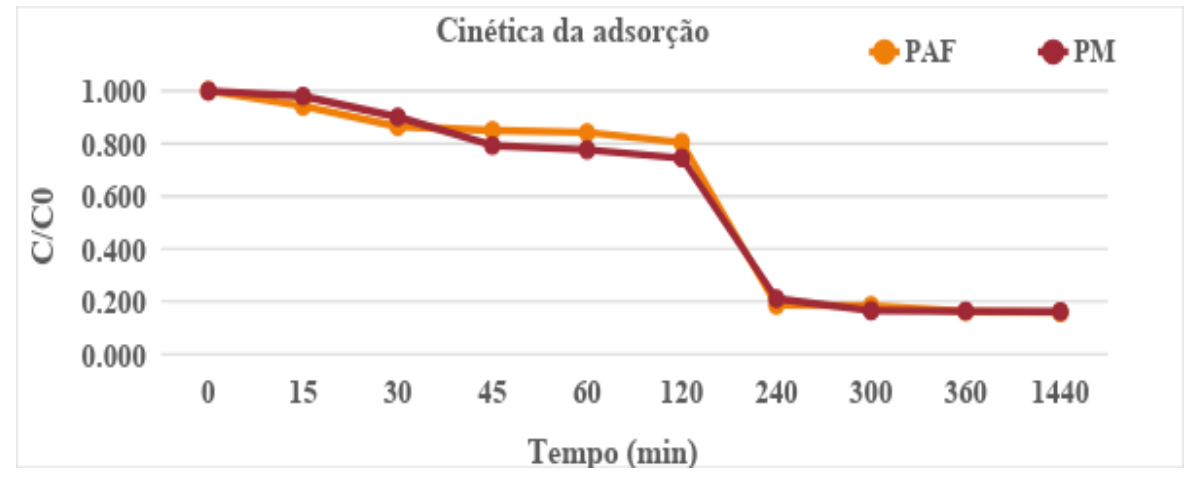

Figura 2 - Cinética da adsorção

Os resultados obtidos demonstraram que, para ambos os resíduos, a adsorção apresentou maior adequação ao modelo de pseudo-primeira ordem, conforme a tabela 1. 


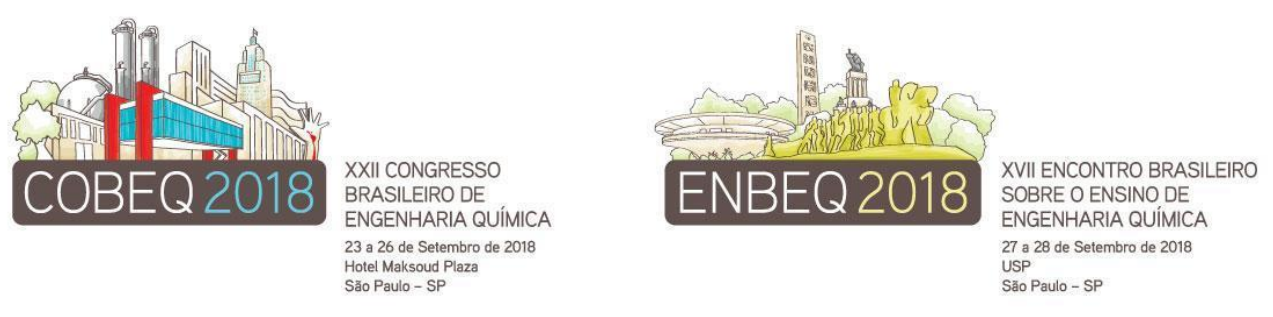

\begin{tabular}{|c|c|c|c|c|}
\hline \multirow{2}{*}{ Ordem } & \multicolumn{2}{|c|}{ pseudo-primeira ordem } & \multicolumn{2}{c|}{ pseudo-segunda ordem } \\
\hline resíduo & PAF & PM & PAF & PM \\
\hline $\mathrm{R}^{2}$ & 0,9368 & 0,9479 & 0,7694 & 0,8061 \\
\hline $\mathrm{k}$ & $0,01603 \mathrm{~min}^{-1}$ & $0,01931 \mathrm{~min}^{-1}$ & $2,76 \mathrm{E}-07 \mathrm{~L} \cdot \mathrm{mg}^{-1} \cdot \mathrm{min}^{-1}$ & $4,02 \mathrm{E}-07 \mathrm{~L} \cdot \mathrm{mg}^{-1} \cdot \mathrm{min}^{-1}$ \\
\hline
\end{tabular}

Tabela 1 - Adequação aos modelos de pseudo-primeira e pseudo-segunda ordem para o PAF e PM

\section{CONCLUSÃO}

A água residuária gerada nas etapas de lavagem do biodiesel apresentou alta carga orgânica e turbidez, confirmando a necessidade de tratamento para seu descarte adequado. No equilíbrio de adsorção, obteve-se remoção da DQO de aproximadamente $80 \%$, o que comprova a eficiência do processo. Conclui-se ainda que o reaproveitamento do PAF e do PM como material adsorvente para tratamento de efluente oriundo da produção do biodiesel é viável e de grande vantagem, favorecendo a sustentabilidade dos processos produtivos.

\section{REFERÊNCIAS}

ANDRADE, L. N.; TEIXEIRA, I. F.; LEÃO, M. M. D.; LAGO, R. M.; AMORIM, C. C. Investigação da capacidade de adsorção/regeneração de resíduo siderúrgico para tratamento de efluentes oleosos. In: Anais do $9^{\circ}$ EBA IBA - Encontro Brasileiro sobre Adsorção \& 1 Simpósio Ibero-Americano sobre Adsorção. Recife 2012.

APHA - AMERICAN PUBLIC HEALTH ASSOCIATION. Standard methods for examination of water and wastewater. $21^{\mathrm{a}}$ ed., Washington D.C., USA, 2005.

GONÇALVES, L. O. Tratamento de efluente da produção de biodiesel pelas combinações de processos biológicos e oxidativos avançados. 2015. 118f. Dissertação (Mestrado em Saneamento, Meio Ambiente e Recursos Hídricos) - Escola de Engenharia da Universidade Federal de Minas Gerais, Belo Horizonte 2015.

OLIVEIRA, I. S. Utilização de resíduo siderúrgico como material alternativo no tratamento de efluentes. 2014. 62 f. Trabalho Final de Curso (Engenheiro Ambiental e Sanitarista) - Universidade Federal de Juiz de Fora, Juiz de Fora. 2014.

SANTOS, A. M. M. Tratamento de efluentes de biodiesel pelo processo combinado de coagulação-floculação e fenton. 2014. 81f. Dissertação (Mestrado em Saneamento, Meio Ambiente e Recursos Hídricos) - Escola de Engenharia da Universidade Federal de Minas Gerais, Belo Horizonte 2014.

SANTOS, V. S. Utilização de resíduos siderúrgicos como adsorventes de baixo custo no tratamento de efluentes contendo emulsões oleosas. 2013. 99 f. Dissertação (Mestrado em Meio Ambiente e Recursos Hídricos) - Programa de Pós-graduação em Saneamento, Meio Ambiente e Recursos Hídricos, Universidade Federal de Minas Gerais, Belo Horizonte. 2013. 